* Mestranda em Direito Negocial (UEL). Especialista em Direito Civil e Processo Civil (UCDB). Especialista em Direito Notarial e Registral (Anhanguera-Uniderp). Oficial de Registro de Imóveis na cidade de Peabiru.

E-mail: dddaia@hotmail.com

** Doutor em Direito: Filosofia do Direito e do Estado, pela Pontifícia Universidade Católica de São Paulo; Mestre em Direito e Pós-graduado em Filosofia Política pela Universidade Estadual de Londrina; Professor adjunto do Departamento de Direito Público da Universidade Estadual de Londrina; Professor no curso de Especialização em Direito Constitucional, na Pontifícia Universidade Católica do Paraná, campus de Londrina; Juiz de Direito (aposentado).

E-mail: sergiodinaura@uol. com.br

\section{A Desjudicialização e os Meios Alternativos de Resolução de Conflitos sob a Égide do Pós- Positivismo}

\author{
Disjudicialization And Alternative Dispute \\ Resolution Under The Post-Positivism Aegis
}

\section{Daiane Schwabe Minelli* Sergio Alves Gomes**}

Como citar: MINELLI, Daiane Schwabe; GOMES, Sergio Alves. A desjudicialização e os meios alternativos de resolução de conflitos sob a égide do pós-positivismo. Revista do Direito Público, Londrina, v. 14, n. 2, p. 151-167, ago. 2019. DOI: 10.5433/24157-108104-1.2019v14n2p. 151. ISSN: 1980-511X

Resumo: Diante do cenário da desjudicialização que vem ganhando destaque a partir da concepção ampliativa do acesso à justiça, sob um enfoque pós-positivista, mostra-se de grande relevo a análise de meios que possam tornar efetivo o acesso a uma ordem jurídica justa. A complexidade e massificação da sociedade hodierna demanda uma resposta jurisdicional célere e efetiva, que concretize o acesso à justiça, o que não vem sendo assegurado adequadamente diante da situação caótica em que se encontra o sistema judicial brasileiro. Nesse sentido, as formas alternativas de resolução de conflito, diante do processo de desjudicialização, representam um significativo avanço, ensejando alterações legislativas em prol da valorização da autonomia privada e da dignidade da pessoa humana.

Palavras-chave: Pós-positivismo. Neoconstitucionalismo. Desjudicialização. Meios alternativos de resolução de conflitos.

\begin{abstract}
Given the scenario of disjudicialization that has gained prominence from the widening conception of access to justice, under a post-positivist doctrine, it is of great importance to analyze the mechanisms that can effectively provide access to a justice. The complexity and massification of today's society demands a speedy and effective judicial response, which should guarantee access to justice, even though it has not been properly guaranteed given the fact that the Brazilian judicial system is at most times chaotic. Hence, the alternative forms of conflict resolution, promoted by the disjudicialization movement. This represents a significant advance, as it can lead to legislative
\end{abstract}


changes that promotes private autonomy and the dignity of the human person.

Key-words: $\quad$ Post-positivism. Neoconstitutionalism. Disjudicialization. Alternative dispute resolution. 


\section{INTRODUÇÃO}

Como fonte de constantes conflitos, a sociedade contemporânea, complexa e pluralista, demanda uma prestação jurisdicional cada vez mais célere e efetiva. Assim, o direito fundamental de acesso à justiça, como um direito que se amolda aos fatos sociais, segue essa mesma tendência, porém, qualificado pelo valor inerente ao Estado Democrático de Direito: a dignidade da pessoa humana.

Esse entendimento encontra respaldo no atual ordenamento jurídico graças à hermenêutica constitucional inspirada pelo modelo pós-positivista, que teve em Ronald Dworkin seu grande expoente, acompanhado de Robert Alexy, ao defender a superação do positivismo com seu modelo de regras formal e impermeável aos valores morais.

No presente cenário pós-positivista o direito não pode ser pensado nos acanhados limites de um sistema normativo puro, baseado exclusivamente em regras, devendo tornar-se permeável a princípios e valores morais que indicam uma direção a seguir, um critério norteador que seja ao mesmo tempo o alicerce e o ápice de qualquer sociedade: a pessoa humana.

A dignidade da pessoa humana representa hoje, portanto, a fonte máxima de toda hermenêutica que se pretenda constitucional e, portanto, deve ser ela a diretriz de toda interpretação dada ao direito fundamental de acesso à justiça, visto por muitos como um simples direito de acesso à tutela jurisdicional, ou mero direito de acesso aos tribunais.

É nesse sentido que se buscará analisar esse direito tão fundamental à existência humana e que promove a efetivação de tantos outros direitos fundamentais: a interpretação humana do acesso à justiça sob a égide pós-positivista, levando em consideração a valorização da autonomia privada e o estímulo à justiça coexistencial por meio da efetivação dos meios alternativos de resolução de conflitos, diante da ampliação do significado do direito de acesso à justiça.

\section{ALGUMAS CONSIDERAÇÕES ACERCA DO PÓS-POSITIVISMO E A DIGNIDADE DA PESSOA HUMANA}

O positivismo jurídico ${ }^{1}$ sempre foi - e continua sendo para alguns -, a única referência de um modelo de regras válido num sistema jurídico: a lei como única fonte legítima para solucionar todas as situações fáticas, devendo ser aplicada de forma independente dos valores morais ${ }^{2}$. É nesse sentido que afirma Calsamiglia (1998, p. 209) que "la teoría positivista del derecho sostiene básicamente que el único objeto de la ciência del derecho es el derecho dictado por los hombres

1 A expressão “positivismo jurídico", de acordo com Norberto Bobbio (1995, p. 15), pode ser encontrada na "locução direito positivo contraposta àquela de direito natural", de forma que, para que se possa compreender o positivismo jurídico, faz-se necessário entender a expressão "direito positivo". Para tanto o autor cita, inicialmente , uma passagem de NottiAttiche, de Aulo Gellio, da época romana, que diz o seguinte: "Quod P. Nigidus argutissime docuit nomina non positiva esse, sed naturalia", distinguindo entre aquilo que é por natureza (physis), ou seja, o direito natural, daquilo que é por convenção, ou posto pelos homens (thésis), isto é, o direito positivo (BOBBIO, 1995, p. 15).

2 Luis Roberto Barroso (2005) afirma que o pós-positivismo pode ser entendido como um movimento jurídicofilosófico ainda em construção, buscando superar os modelos do jusnaturalismo e do positivismo. 
y que, además, la teoría posee los métodos adecuados para determinar qué es lo que establece el derecho".

Ronald Dworkin (2002) demonstrou de forma original e combativa, a necessidade de superar a teoria positivista ${ }^{3}$, que defende o apego às regras jurídicas, conforme sua análise crítica das concepções de John Austin (direito como comandos do soberano) e, principalmente, de H.L.A. Hart (direito como conjunto de regras primárias e secundárias), ao demonstrar que esses modelos de regras são insuficientes para resolver a complexidade de casos concretos ("casos difíceis") que emergem nos tribunais, insistindo numa leitura moral da Constituição e "denunciando a hipocrisia do pressuposto da neutralidade proposta pelo positivismo" (CALSAMIGLIA, 1998, p. 213) reconhecendo a importância dos princípios.

Ao analisar alguns casos concretos de tribunais norte-americanos, em que regras jurídicas foram afastadas diante de máximas gerais ${ }^{4}$, critérios de equidade e de justiça, afirma Dworkin (2002, p. 39) que a diferença entre regras e princípios é de natureza lógica, posto que ambos apontam para decisões particulares acerca da obrigação jurídica em situações específicas, mas “distinguem-se quanto à natureza da orientação que oferecem”, sendo que as regras são aplicáveis à maneira do "tudo-ou-nada": ou a regra é válida e então, a resposta que oferece para os fatos que estipula, deve ser aceita, ou não é válida e, portanto, de nada adianta para a decisão (DWORKIN, 2002, p. 39).

Para o autor, princípio seria "um padrão que deve ser observado" por ser uma "exigência de justiça ou equidade ou alguma outra dimensão da moralidade" (DWORKIN, 2002, p. 36), sem apresentar "consequências jurídicas que se seguem automaticamente quando as condições são dadas", nem "estabelecer condições que tornem sua aplicação necessária", sendo que apenas enunciam uma razão hábil a conduzir o argumento em certa direção, necessitando ainda de uma decisão particular (DWORKIN, 2002, p. 40). Os princípios possuem a dimensão do peso ou importância, ausente nas regras, de modo que quando em conflito, quem vai resolvê-lo deve levar em consideração a força relativa de cada um. Quanto às regras, quando em conflito, uma delas não se mostra válida ${ }^{5}$ (DWORKIN, 2002, p. 43).

De acordo com Bittar e Almeida (2018, p. 530), entende Dworkin que normas e princípios compõem o sistema jurídico, "na medida em que normas válidas se aplicam, e normas jurídicas inválidas não se aplicam, enquanto que princípios sempre se aplicam, com maior ou menor intensidade aqui e ali, mas sempre serão considerados subsídios para que a interpretação de cada

3 A despeito da interessante evolução histórica de que emergiu o positivismo jurídico, passando pelas concepções de Montesquieu no século XVIII, pela escola histórica e pelo rigor da escola da exegese do início do século XIX, na França, apenas para citar alguns marcos, destacam-se como expoentes desse modelo de regras, tomando aqui como base o estudo de Dworkin em "Levando os Direitos à Sério", os ingleses John Austin, no século XIX, com sua concepção do direito como comando, e Herbert L.A. Hart, com sua obra "The concept of law" (O conceito de Direito).

4 Um dos exemplos citados pelo autor é de uma decisão do Tribunal de Nova Iorque (Riggs contra Palmer - 1889), no sentido de que, o assassino do avô, mesmo contemplado no testamento, não teve o direito à herança, diante do princípio segundo o qual a ninguém será permitido lucrar com a sua própria fraude, beneficiar-se com seus próprios atos ilícitos (DWORKIN, 2002, p. 37).

5 Prossegue o autor: “Um sistema jurídico pode regular esses conflitos través de outras regras, que dão precedência à regra promulgada pela autoridade de grau superior, à regra promulgada mais recentemente, à regra mais específica ou outra coisa desse gênero. Um sistema jurídico também pode preferir a regra que é sustentada pelos princípios mais importantes" (DWORKIN, 2002, p. 43). 
caso esteja escorada em valores morais de grande força e peso socioinstitucional" ${ }^{6}$.

Com base nesses e em outros estudos, e diante da crise pela qual passava o positivismo, novas ideias ganharam força no sentido de aproximar o direito da moral emergindo o pensamento jusfilosófico do pós-positivismo. Esse movimento trouxe a lume, inicialmente, a importância dos princípios e valores para a interpretação da lei ${ }^{7}$, consagrando a importância do homem e a sua função como norte axiológico de todo o ordenamento jurídico e demandando a proteção da dignidade da pessoa humana e dos direitos fundamentais. Segundo Sergio Alves Gomes (2011, p. 215), essa perspectiva "revela cada vez mais que, sem a inclusão dos valores no âmbito jurídico, o Direito se resumiria a um arcabouço de normas passíveis de qualquer conteúdo, inclusive daqueles que ao invés de dignificar o ser humano, poderiam convertê-lo em mera 'coisa", como a escravidão, que foi disciplinada e legitimada pelo ordenamento jurídico.

Com a superação do positivismo, abriu-se segundo Barroso (2005, p. 4) "caminho para um conjunto amplo e ainda inacabado de reflexões acerca do Direito, sua função social e sua interpretação", que caracterizam o pós-positivismo, na medida em que busca "ir além da legalidade estrita", sem desprezar o direito posto, recorrendo a uma leitura moral do Direito, sem recorrer a categorias metafísicas (BARROSO, 2005, p. 4). Para o autor:

[...] O pós-positivismo é a designação provisória e genérica de um ideário difuso, no qual se incluem a definição das relações entre valores, princípios e regras, aspectos da chamada nova hermenêutica e a teoria dos direitos fundamentais. [...] O Direito, a partir da segunda metade do século XX, já não cabia mais no positivismo jurídico. A aproximação quase absoluta entre Direito e norma e sua rígida separação da ética não correspondiam ao estágio do processo civilizatório e às ambições dos que patrocinavam a causa da humanidade. Por outro lado, o discurso científico impregnara o Direito. Seus operadores não desejavam o retorno puro e simples ao jusnaturalismo, aos fundamentos vagos, abstratos ou metafísicos de uma razão subjetiva. Nesse contexto, o pós-positivismo [...] inicia sua trajetória guardando deferência relativa ao ordenamento positivo, mas nele reintroduzindo as ideias de justiça e legitimidade. O constitucionalismo moderno promove, assim, uma volta aos valores, uma reaproximação entre ética e Direito [...] (BARROSO, 2006, p. 27-28).

O modelo de regras de Dworkin mostra-se de grande importância pela sua natureza crítica ao positivismo e por promover a ideia de que o Direito não pode ser entendido apenas como um conjunto de regras, sendo também integrado por princípios, vinculando valores morais ao direito, principalmente diante dos casos difíceis, em que os princípios desempenham um papel

6 No mesmo sentido, ensina Bonavides (2003, p. 282) ao analisar a contribuição de Dworkin para a teoria dos princípios que "um princípio aplicado a um determinado caso, se não prevalecer, nada obsta a que, amanhã, noutras circunstancias, volte ele a ser utilizado, e já então de maneira decisiva”. E completa o autor, diferenciando esse entendimento daquele aplicado a um sistema de regras, em que "não se pode dizer que uma regra é mais importante do que outra". Não se pode dizer, portanto, que uma regra prevalece sobre outra devido ao seu maior peso (BONAVIDES, 2003, p. 282).

7 Miguel Reale já relacionava direito e valores morais, ao afirmar que: "O certo é que toda norma enuncia algo que deve ser, em virtude de ter sido reconhecido um valor como razão determinante de um comportamento declarado obrigatório. Há, pois, em toda regra um juízo de valor, cuja estrutura mister é esclarecer, mesmo porque ele está no cerne da atividade do juiz ou do advogado" (REALE, 2001, p. 31). 
fundamental ${ }^{8}$, em razão de seu caráter vinculante (DWORKIN, 2002, p. 56-57). Estará, assim, resguardada a efetivação dos direitos fundamentais, não com base em uma racionalidade apodítica, segundo Bittar e Almeida (2018, p. 537), mas buscando sempre o razoável, por meio de uma leitura moral do direito. Nesse contexto, em que "a ideia de racionalidade jurídica aproxima-se da ideia do razoável, e deixa de se identificar à lógica formal das ciências exatas" (SARMENTO, 2009, p. 119), estrutura-se o marco filosófico do novo direito constitucional (BARROSO, 2005, p. 4), o neoconstitucionalismo 9 .

Por meio desse movimento, expressão do paradigma pós-positivista, e pela força atribuída aos princípios, o Poder Judiciário passou a atuar mais ativamente na defesa dos valores constitucionais e a Constituição passa a ser a referência, o norte do ordenamento jurídico e da jurisprudência, como uma das fontes criadoras do direito (SARMENTO, 2009). As Constituições passam a veicular alto teor axiológico, iniciando uma nova etapa: a constitucionalização do ordenamento jurídico, levando a uma nova maneira de interpretar e entender a atuação do judiciário, tendo como fundamento a constituição. Passam os princípios, portanto, a assumir importância vital para o ordenamento jurídico, "sobretudo se lhes analisarmos a função e presença no corpo das Constituições contemporâneas, onde aparecem como os pontos axiológicos de mais alto destaque e prestígio" (BONAVIDES, 2003, p. 289) ${ }^{10}$.

Nesse contexto, verifica-se no neoconstitucionalismo, o ideal humanitário e uma perspectiva otimista, com o aprofundamento "do projeto político da Modernidade, de emancipação pelo uso da razão, através dos instrumentos do Direito Constitucional, sobretudo os direitos fundamentais" (SARMENTO, 2009, p. 123). No que tange à relação entre direito e moral, Sarmento explica que:

As fronteiras entre Direito e Moral não são abolidas, e a diferenciação entre eles, essencial nas sociedades complexas, permanece em vigor, mas as fronteiras entre os dois domínios tornam-se muito mais porosas, na medida em que o próprio ordenamento incorpora, no seu patamar mais elevado, princípios de justiça, e a cultura jurídica começa a levá-los a sério (SARMENTO, 2009, p. 121).

Ao analisar as características do que chama de "constitucionalização do Direito", Figueroa menciona Ricardo Guastini, para quem a constitucionalização é o processo e o resultado

8 Segundo o autor, depois que o caso é decidido, ele ilustra uma regra particular que não existia antes, de forma a justificar uma nova interpretação da lei, podendo o juiz, inclusive, alterar uma regra diante de um princípio, quando este for mais importante do que outros. (DWORKIN, 2002, p. 46).

9 Para alguns autores, o termo pós-positivismo representa mera "nomenclatura de transição", tendo expressado apenas a fase inicial do que hoje chamamos de neoconstitucionalismo, segundo Eduardo Ribeiro Moreira (2008, p. 48). Sarmento (2009, p. 115) afirma que não existe um único neoconstitucionalismo, mas diversas visões sobre o fenômeno jurídico na contemporaneidade, que guardam entre si alguns denominadores comuns relevantes que justifica serem agrupadas sob um mesmo rótulo. Fernandes e Bicalho (2011, p. 111) afirmam que o pós-positivismo é o embasamento da filosofia do direito para o neoconstitucionalismo: o pós-positivismo é a "matriz jusfilosófica que embasa as ideias neoconstitucionais".

10 O estudo acerca da juridicidade dos princípios encontra em Paulo Bonavides (2008, p. 259-266) uma contextualização em que se visualizam três fases: 1 - Jusnaturalista: os princípios reconhecidos dentro de sua esfera ético-valorativa, pela ideia que inspira os postulados de justiça; 2 - Positivista: os princípios eram compreendidos como fonte normativa subsidiária, hierarquicamente subordinados às leis e com reconhecidos se contidos nas leis; 3 - Pós-positivismo: os princípios atingem grande prestígio jurídico-normativo, sendo conduzidos pela nova hermenêutica constitucional, sob a égide contemporânea da hegemonia axiológica. Esse momento é marcado pela admissão dos princípios constitucionais como norteadores de todo o ordenamento jurídico. 
da transformação do Direito causado pela Constituição. São características de um sistema constitucionalizado, segundo o autor: uma constituição rígida; uma garantia jurisdicional da constituição (controle de constitucionalidade); a força vinculante da constituição, que deve ser considerada como verdadeira norma jurídica; sobre-interpretação, que enaltece a analogia e a invocação de princípios constitucionais de forma a responder toda e qualquer controvérsia; a aplicação direta da constituição; a interpretação das leis conforme a constituição e a influência da constituição nas relações políticas (FIGUEROA, 2003, p. 163-164).

Desse processo de constitucionalização do pensamento jurídico decorre o termo constitucionalismo e, mais precisamente, o neoconstitucionalismo ${ }^{11}$, que é o conjunto de teorias que vem proporcionando uma cobertura justeórica conceitual e/ou normativa na constitucionalização do Direito em termos normalmente não positivistas (FIGUEROA, 2003, p. 164).

No Brasil, o neoconstitucionalismo ${ }^{12}$ decorre do processo de redemocratização, trazido pela Constituição Federal de 1988, que possibilitou o rompimento com a ordem até então vigente, trazendo "amplo e generoso elenco de direitos fundamentais de diversas dimensões - direitos individuais, políticos, sociais e difusos - aos quais conferiu aplicabilidade imediata (art. $5^{\circ}$, Parágrafo $1^{\circ}$ ) e protegeu diante do próprio poder de reforma" (SARMENTO, 2009, p. 125). Esse paradigma denota a necessidade de uma aplicação mais justa do Direito, atribuindo ao intérprete o dever de construção de sentido (GOMES, 2011, p. 93), tendo o homem como protagonista do ordenamento jurídico.

Nesse sentido, as ideias de Dworkin e Alexy ganham destaque na medida em que enfatizam "o caráter normativo e a importância dos princípios constitucionais", com destaque para a influência dos direitos fundamentais, passando a emergir a "preocupação com valores e democracia, repleta de novas categorias, importadas, sobretudo do Direito germânico, como o 'mínimo existencial', a 'reserva do possível' e a 'proibição do retrocesso"” (SARMENTO, 2009, p. 127). O neoconstitucionalismo abre, pois, as portas do Direito para o debate moral, "ao reconhecer a força normativa de princípios revestidos de elevada carga axiológica, como dignidade da pessoa humana, igualdade, Estado Democrático de Direito e solidariedade social” (SARMENTO, 2009, p. 120).

Nesse cenário neoconstitucionalista, a dignidade da pessoa humana deixa de ser vista apenas como uma regra de aplicação limitada, para consolidar-se como um valor ético fundamental que embasa um princípio de observância obrigatória para a própria manutenção da existência humana. É nesse sentido que segue o conceito de dignidade da pessoa humana desenvolvido por Ingo Wolfgang Sarlet:

11 Para o autor, são aspectos do constitucionalismo: o aspecto material da constituição, com o Direito representado por um forte carga axiológica, oposta ao positivismo jurídico; o aspecto estrutural da constituição, que elenca a estrutura das normas constitucionais (princípios constitucionais que permitem a onipresença da Constituição de Alexy e a ponderação, como um sistema dinâmico de argumentos); e o aspecto político, que permite o protagonismo do judiciário (FIGUEROA, 2003, p. 165-167).

12 No Brasil, o uso do termo neoconstitucionalismo foi utilizado a partir da obra Neoconstitucionalismo(s), organizada por Miguel Carbonell e publicada em 2003. Alguns autores aderiram explicitamente à corrente (Luis Roberto Barroso, Lênio Luiz Streck, Antonio Cavalcanti Maia, Ana Paula de Barcellos, Diogo de Figueiredo Moreira Neto, Paulo Ricardo Schier, Eduardo Moreira, Écio Otto Ramos Duarte e Thomas Rosa de Bustamante); outros a criticaram (José Ribas Vieira, Dimitri Dimoulis e Humberto Ávila). (SARMENTO, 2009, p. 129). 
A qualidade intrínseca e distintiva de cada ser humano que o faz merecedor do mesmo respeito e consideração por parte do Estado e da comunidade, implicando, neste sentido, um complexo de direitos e deveres fundamentais que asseguram a pessoa tanto contra todo e qualquer ato de cunho degradante e desumano, como venham a lhe garantir as condições existenciais mínimas para uma vida saudável, além de propiciar e promover sua participação ativa co-responsável nos destinos da própria existência e da vida em comunhão dos demais seres humanos (SARLET, 2001, p. 60).

Assim, pode-se conceituar dignidade da pessoa humana como uma qualidade inerente ao ser humano, que o torna digno de respeito pela sociedade e pelo Estado, devendo a ele ser assegurados os direitos fundamentais de que depende para ter uma existência digna, ou em outras palavras, as condições mínimas de sobrevivência. Para a doutrina em geral, costuma-se mencionar a garantia de um mínimo existencial, composto por esse núcleo mínimo de direitos, sem os quais se pode afirmar que o indivíduo se encontra em situação de indignidade. Nesse sentido, deve ser considerada a implementação dos direitos à educação básica, à saúde, à assistência social e o acesso à justiça (BARCELLOS, 2002, p. 305).

Trata-se de garantia essencial à organização da vida em sociedade e fundamental à própria manutenção da existência humana, na medida em que assegura condições mínimas, básicas e indispensáveis a ela. É por isso que sem o seu reconhecimento, como elemento de todo ser humano, "os demais valores ficam sem uma referência que lhes possibilite produzir sentido coerente com a ideia de democracia." (GOMES, 2011, p. 284).

Nesse sentido é que se pode afirmar que ocupa a posição de alicerce do Estado Democrático de Direito, ou seu fundamento, conforme estabelece a própria Constituição Federal em seu art. $1^{0}$, III, emanando efeitos sobre todo o ordenamento jurídico e fortalecendo os ideais de liberdade e cidadania na busca de progresso e pacificação social, na medida em que, é por respeito ao valor maior da dignidade da pessoa humana que os demais valores (vida, liberdade, igualdade, segurança, justiça, propriedade) devem ser assegurados (GOMES, 2011, p. 284).

\section{O ACESSO À JUSTIÇA COMO DIREITO FUNDAMENTAL}

O caminho para a consolidação do princípio constitucional da dignidade da pessoa humana passa, principalmente, pelo efetivo acesso à justiça, que possa proporcionar a concretização dos direitos fundamentais que integram aquele núcleo mínimo de existência digna de todos os seres humanos. Para tanto, é necessário compreender que a concepção clássica e formal de acesso à justiça deve passar por uma releitura à luz do modelo pós-positivista do direito em seu viés neoconstitucionalista.

Com base em seu poder de império, o Estado chamou para si o poder de resolver conflitos sociais com definitividade, por meio da garantia constitucional da inafastabilidade do Poder Judiciário ou da proteção judiciária, não sendo permitido aos indivíduos realizar justiça com as 
próprias mãos. De acordo com a Constituição Federal, na redação do artigo 50, inciso XXXV, "a lei não excluirá da apreciação do Poder Judiciário, lesão ou ameaça a direito.” Houve assim, expressa vinculação do direito fundamental de acesso à justiça à necessária intervenção do Estado-juiz.

Com a passagem do Estado Liberal para o Estado Social, o acesso à Justiça passou a ser reconhecido como requisito fundamental de um sistema que vise garantir - e não apenas proclamar - direitos de todos, sendo "o mais básico dos direitos humanos" (CAPPELLETTI; GARTH, 1988, p. 12). Diante da visão pós-positivista dos princípios, tendo como base a dignidade da pessoa humana, fundamento de um Estado Democrático de Direito, o acesso à justiça passa a ser reconhecido como um direito fundamental, uma vez que é por meio de sua garantia que pode ser dada adequada tutela aos direitos fundamentais dos indivíduos. Quer-se com isso dizer que a ele deve ser atribuída uma conotação diversa, que o identifique como um direito-garantia, na medida em que por meio dele é possível que as pessoas exerçam sua cidadania e provoquem o reconhecimento de outros direitos essenciais à vida humana.

As constantes transformações sociais e o surgimento de necessidades mais complexas diante do advento de novos interesses promoveram essa alteração de entendimento, uma vez que o acesso à justiça não poderia mais limitar-se apenas ao direito de pleitear solução de conflitos perante o Poder Judiciário, mas de garantir o efetivo acesso a uma ordem jurídica justa e tempestiva (WATANABE, 2011, p. 385). Nesse sentido, conclui Sardinha (2018, p. 17) ao afirmar que "não pode assumir a significância exclusiva de acessibilidade ao Poder Judiciário, haja vista que o referido termo abarca também o acesso a toda uma ordem de direitos e valores".

$\mathrm{O}$ acesso à justiça tem se consolidado, portanto, não apenas como um direito formal, de acesso aos tribunais, mas também como direito de acesso a uma ordem jurídica justa (WATANABE, 2011, p. 385), que efetivamente proporcione uma tutela que promova a realização do direito material e voltado, essencialmente, à pacificação social (DINAMARCO, 1996, p. 20). Assim é que se entende que uma sociedade justa e igualitária só existe quando há "a aplicabilidade efetiva do direito de acesso à justiça", tendo em vista que "tal direito é, por lógica, a condição primeira e essencial, para que os outros direitos que também são de natureza fundamental sejam efetivados" (SARDINHA, 2018, p. 14).

Entretanto, o exercício excessivo desse direito-garantia, embora essencialmente destinado à efetivação de direitos e à consolidação de um Estado Democrático de Direito, acabou por trazer consequências negativas para a sociedade atual. A amplitude desse acesso estimulou um processo de judicialização, ou seja, de crescimento de litígios cíveis, gerando a situação caótica em que encontra esse órgão atualmente, congestionado e com alto grau de morosidade. Teve então início, um grande problema, segundo Suter e Cachapuz (2016, p. 59):

O Estado ao conceder acesso amplo e irrestrito à justiça não estava preparado para maior número de demandas nos tribunais. Assim, insatisfações e reclamações no tocante a lentidão nas resoluções dos litígios, mostraram a ingerência e a desorganização do Poder Judiciário Brasileiro a dar resposta ao cidadão e a promover a paz social. 
O Poder Judiciário, engessado em razão do formalismo excessivo e da enorme quantidade de processos, não se mostra mais apto a lidar com a enorme quantidade de lides que vem se formando, gerando uma significativa restrição à garantia de acesso daqueles que dependem de uma atuação estatal.

Nesse cenário, sob a ótica da hermenêutica constitucional pós-positivista, emerge a preocupação com a efetivação do princípio da dignidade da pessoa humana, cuja realização é dever fundamental do Estado. Reconheceu essa necessidade o Supremo Tribunal Federal ao afirmar que: “A prestação jurisdicional é uma das formas de se concretizar o princípio da dignidade humana, o que torna imprescindível seja ela realizada de forma célere, plena e eficaz" (Reclamação n ${ }^{0} 5.758$. Rel. Min. Cármen Lúcia - julgado em 13/05/2009. Plenário DJE de 07/08/2009). Mais do que um princípio, o acesso à justiça destaca-se, segundo Cândido Dinamarco, “como síntese de todos os princípios e garantias do processo, tanto no âmbito constitucional quanto infraconstitucional, em sede legislativa, doutrinária e jurisprudencial”. (DINAMARCO, 1996. p. 303).

Soma-se, assim, a esse cenário a inafastável garantia da razoável duração do processo, positivada no art. $5^{\circ}$, inciso LXXVIII, da Constituição Federal, por meio da Emenda Constitucional $n^{0} 45 / 2004$, porém garantida há muito por alguns instrumentos internacionais, como a Convenção Europeia de Direitos Humanos e o Pacto de São José da Costa Rica (Convenção Americana sobre Direitos Humanos), enunciando em termos gerais que todo indivíduo tem direito à devida prestação jurisdicional em prazo razoável por um tribunal independente e imparcial, condenando o atraso na prestação jurisdicional.

Essa nova perspectiva do direito de acesso à justiça muito se deve aos estudos realizados por Mauro Cappelletti e Bryant Garth em seu projeto Florença, ao analisar os problemas que envolvem a prestação jurisdicional e geram restrição àquele direito fundamental. Entendem os autores ser necessário o atendimento a duas finalidades do sistema jurídico: a acessibilidade igualitária a todos e a produção de resultados individual e socialmente justos (CAPPELLETTI; GARTH, 1988, p. 8), propondo as soluções por eles denominada de "ondas renovatórias" de universalização do acesso ${ }^{13}$.

Como objeto da terceira onda renovatória encontra-se a remoção dos obstáculos processuais que impedem um resultado rápido, eficiente e satisfatório do conflito. A partir dessa conclusão, novo enfoque deve ser dado ao acesso à justiça, mediante a busca de novas formas de resolver os conflitos, dando ênfase à atividade extrajudicial, uma vez que não pode a via jurisdicional ser considerada o único caminho que conduz à Justiça.

Essa busca de novos caminhos, conforme ensinamento de Fernanda Tartuce, "há de ser multifacetada", abrangendo meios variados de solução de controvérsias, que possam ser eficazmente tratados por técnicas peculiares (TARTUCE, 2018, p. 36). Assim, dentro da perspectiva da dignidade

13 A primeira solução para o acesso - a primeira "onda" desse movimento novo - foi a assistência judiciária; a segunda dizia respeito às reformas tendentes a proporcionar representações jurídicas para interesses "difusos", especialmente nas áreas da proteção ambiental e do consumidor; e o terceiro - e mais recente - é o que nos propomos a chamar simplesmente "enfoque de acesso à justiça", porque inclui os posicionamentos anteriores, mas vai muito além deles, representando, dessa forma, uma tentativa de atacar as barreiras ao acesso de modo mais articulado e compreensivo (CAPPELLETTI; GARTH, 1988, p. 28). 
da pessoa humana e, tendo como pano de fundo, a inspiração pós-positivista, faz-se necessário pensar além, de forma a assegurar a autonomia privada dos indivíduos e implementar medidas que propiciem a mais adequada solução de seus problemas jurídicos, como direito fundamental de acesso a uma ordem jurídica justa.

\section{A DESJUDICIALIZAÇÃO E OS MEIOS ALTERNATIVOS DE SOLUÇÃO DOS CONFLITOS SOB A ÉGIDE DO PÓS-POSITIVISMO}

Diante do contexto atual em que se encontra a teoria dos princípios, denominado por Paulo Bonavides de "estado principial" (BONAVIDES, 2003, p. 293), mostra-se importante analisar o movimento da desjudicialização no Brasil e sua relevância para a efetividade da dignidade da pessoa humana, sob a égide do pós-positivismo, considerando que a morosidade do Poder Judiciário tem, de fato, potencial para lesar direitos fundamentais que deveriam ser tutelados pelo Estado.

O reconhecimento do individuo como universo de valores promovido pelo liberalismo gerou uma sociedade pluralista e multicultural, que demanda respostas rápidas, úteis e adequadas, tornando inviável ao cidadão a busca pelo Poder Judiciário como única via de acesso para resolução de conflitos. Verifica-se uma insatisfação crescente com os processos autoritários de tomada de decisões, que não se adequam aos interesses das partes, e possuem custos elevados (MUNIZ, 2014, p. 56). Daí surgir a necessidade de uma política de desjudicialização, que estimule a resolução de conflitos de outras formas ${ }^{14}$.

O processo de desjudicialização trouxe a possibilidade da resolução consensual de conflitos na via extrajudicial, como uma opção plausível para a resolução de problemas jurídicos, por meio da conciliação e da mediação ${ }^{15}$. Esses meios de resolução de conflitos mostram-se como importantes instrumentos para preservar a dignidade humana, num contexto de expansão da democracia e da autonomia privada.

Analisando o movimento de desjudicialização que vem ocorrendo em Portugal dentro de um contexto maior, por ele denominado "desjuridificação", e que pode ser aplicado ao sistema brasileiro pela similaridade de cenários, Pedroso (2002, p. 17) afirma que o processo de desjudicialização decorre de um contexto de reforma da administração da justiça, que permite a prevenção de um litígio:

\footnotetext{
14 Os meios jurisdicionais mostram-se cada vez mais ineficientes e insuficientes com o desenvolvimento contínuo da humanidade, constatando Tânia Lobo Muniz que essa situação levou à busca "de procedimentos alternativos ao juízo estatal, menos formais, mais eficazes na resolução efetiva das questões e que possibilitem uma maior pacificação e justiça, conduzindo aos meios alternativos de resolução de conflitos, dentre as quais destacam-se a arbitragem e a negociação, que pode se dar por meio da conciliação e da mediação" (MUNIZ, 2014, p. 34).

15 Conforme os parágrafos $2^{\circ}$ e $3^{\circ}$ do art. 165 do Código de Processo Civil, na conciliação, um terceiro imparcial atuará como conciliador preferencialmente nas situações em que não existia vinculo anterior entre as partes, podendo sugerir soluções para o litígio, uma vez que o intuito é obter o acordo. Por outro lado, na mediação, o mediador atua preferencialmente nas situações em que há vinculo anterior entre as partes, auxiliando os interessados a compreender os conflitos, restabelecendo a comunicação entre os mesmos, de forma que as soluções consensuais gerem benefícios mútuos (SARDINHA, 2018, p. 92).
} 
Os processos de desjuridificação incluem ainda as categorias de "informalização da justiça" e de "desjudicialização" [...] através de criação de processos, instâncias e instituições descentralizadas, informais e desprofissionalizadas que assumem a resolução de litígios outrora privativa dos tribunais judiciais. Os conceitos de informalização e desjudicialização, em sentido amplo, manifestam-se através de diferentes realidades que permitem prevenir ou resolver um litígio, ou seja, um conflito social que dois ou mais interessados pretendam que seja dirimido sem recurso ao tribunal judicial (PEDROSO, 2002, p. 18).

As primeiras referências a esse movimento encontradas no Brasil foram inspiradas na segunda metade do século XX, pelo movimento internacional gerado pelas ondas renovatórias do acesso à justiça (relatório Florença ${ }^{16}$ ), quando passou a haver um grande incremento de normas no sentido de promover a desobstrução do sistema judicial. Políticas públicas nesse sentido passaram a ser promovidas, tendo por enfoque o estímulo aos chamados "meios alternativos de resolução de conflitos" (MARCs), em alusão ao seu correspondente inglês "Alternative Dispute Resolution" (ADR). Nesse sentido, destaca-se a Política Judiciária Nacional de tratamento adequado dos conflitos de interesses, implementada pelo Conselho Nacional de Justiça, por meio da Resolução $\mathrm{n}^{0} 125 / 2010$.

Ao estabelecer uma política pública de estímulo à resolução consensual de conflitos de forma extrajudicial, o Conselho Nacional de Justiça apresentou um modelo em que busca ampliar o acesso à justiça e estimular um comportamento mais ativo das pessoas que estão envolvidas no conflito, considerando que a conciliação e a mediação são instrumentos efetivos de pacificação social, solução e prevenção de litígios, e que a sua apropriada disciplina tem reduzido a excessiva judicialização dos conflitos de interesses e a quantidade de recursos.

Embora destinada ao âmbito judicial, essa normativa promoveu o primeiro passo rumo a um novo enfoque dado aos conflitos por meio de uma política pública permanente de incentivo e aperfeiçoamento daqueles meios, ao qual se seguiram o Código de Processo Civil (Lei $\mathrm{n}^{0}$ 13.105/2015), a Lei $n^{0}$ 13.140/2015 (lei de mediação) e o Provimento nº 67/2018 do Conselho Nacional de Justiça.

A conciliação e a mediação passam a ser oficialmente consideradas como efetivos instrumentos de pacificação social, tanto na solução quanto na prevenção de litígios, diante da redução da judicialização de conflitos que são capazes de promover. Esse também foi um dos motivos pelo qual o Código de Processo Civil de 2015 trouxe em seu art. $3^{\circ}, \S \S 2^{\circ}$ e $3^{\circ}$, previsão no sentido de priorizar a realização de conciliação, mediação e outros métodos de solução consensual de conflitos, apresentando-os como princípio geral para o direito processual civil (SUTER, 2018, p. 15).

Ao dar preferência à opção pelos métodos extrajudiciais de solução de conflitos, o Código de Processo Civil, conforme interpretação de seu artigo $3^{\circ}$, oportunizou a busca pela solução

16 O projeto Florença foi coordenado por Mauro Cappelletti, em colaboração com Bryant Garth e Nicolò Trocker retratando, a partir de estudos empíricos, em três ondas renovatórias, os entraves para o acesso à Justiça (MENDES; SILVA, 2015. p. 1827-1858). 
jurídica mais adequada pelas partes, além da via judicial, buscando instaurar uma cultura de paz, demonstrando a adoção de um "sistema multiportas de acesso à justiça"17, idealizado por Frank Sander ("Multidoor Couthouse system"), que busca oferecer soluções diversas do Judiciário e mais adequadas às peculiaridades de cada demanda (TARTUCE, 2018, p. 72).

Nessa toada foi publicada a lei $n^{0} 13.140 / 2015$, que trata da mediação como meio de solução de controvérsias entre particulares, sendo seu marco legal no país. A opção pela via extrajudicial de acesso à justiça, segundo Sardinha (2018,p. 39), “confere aos cidadãos uma maior liberdade e poder de decisão sobre a forma como será solucionado o seu caso concreto, reduzindo a interferência do Estado que não mais substitui a vontade das partes por meio de uma decisão judicial”. Por meio dessa via, podem ser atendidos a necessidade individual das partes, que não ficam dependentes da morosidade e dos entraves do sistema judicial, e também, o interesse coletivo, uma vez que, em longo prazo, haverá progressiva desobstrução daquele sistema e maior pacificação social, como objetivo comum de uma sociedade.

Ao possibilitar a realização de autocomposição das partes em centros extrajudiciais, a desjudicialização veio ao encontro da realização da democracia, incentivando comportamentos que desenvolvem a cidadania e oportunizando aos envolvidos uma posição de protagonismo na busca da solução mais adequada ao seu problema jurídico, em prol da liberdade negocial e dando maior efetividade à dignidade da pessoa humana. Com isso, constrói-se a sociedade correspondente a um Estado Democrático de Direito que, segundo Tania Lobo Muniz, "deve ser construída diariamente por meio da persecução de valores como a liberdade e a igualdade; do exercício da cidadania pelo povo, alcançada pelo desenvolvimento cultural e pela educação; e pelo exercício do poder voltado para os interesses sociais" (MUNIZ, 2014, p. 43).

Diante de uma sociedade cada vez mais complexa e pluralista, o afastamento de conflitos da justiça tradicional possibilita a sua resolução por meio do consenso ${ }^{18}$ entre as pessoas, uma vez que aquela via não satisfaz adequadamente às suas necessidades, abrindo caminho para a valorização da justiça coexistencial ou conciliatória, mediante o reconhecimento de ser o próprio indivíduo o responsável por seu destino. É essa a solução trazida por Cappelletti, no sentido de contrapor a justiça contenciosa, baseada na decisão adjudicada ${ }^{19}$, pela ideia da justiça coexistencial (CAPPELLETTI, 1992, p. 128).

De acordo com Cappelletti, a oralidade, como pressuposto de uma justiça conciliatória, sempre representou forma de democratização e de garantia maior do contraditório participativo, de forma a tornar possível um "remendo" de uma "situação de ruptura ou tensão, em vista da preservação de bem mais duradouro, a convivência pacífica de sujeitos que fazem parte de um

17 A doutrina considera a adoção de um "sistema multiportas" de acesso à justiça no Brasil, termo cunhado pelo americano Frank Sander ("MultiDoors CourtHouse") para se referir à possibilidade de escolha de diferentes métodos de resolução de conflitos integrados ao Judiciário (ALMEIDA, 2015, p. 85).

18 Segundo Tania Lobo Muniz, citando Martinelli, "a negociação sempre envolve movimento em busca de um consenso que é a [...] concordância genuína graças a total coincidência das visões, das necessidades e dos desejos legítimos dos diversos participantes" (2014, p. 35).

19 Cappelletti entende ser necessário o estímulo à justiça em bases conciliatórias, de forma a "por um limite às intervenções da máquina do Estado, que com frequência se revelou demasiado lenta, formal, rígida, burocraticamente opressiva" (CAPPELETTI, 1992, p. 134). 
grupo ou de uma relação complexa" (CAPPELLETTI, 1992, p. 133). Esse é o objetivo da justiça coexistencial, ou seja, a resolução de conflitos que surgem no cotidiano dos indivíduos como integrantes de um grupo social, como "justiça que tenha em vista a inteira situação na qual se insira o episódio contencioso, e que tenda a ‘curar', não exasperar, a situação de tensão.”(CAPPELLETTI, 1992, p. 133).

Com a política pública de estímulo à resolução consensual de conflitos de forma extrajudicial, o Conselho Nacional de Justiça apresentou, portanto, um modelo de justiça coexistencial $^{20}$, em que se busca ampliar o acesso à justiça e estimular um comportamento mais ativo das pessoas que estão envolvidas no conflito, considerando que a conciliação e a mediação são instrumentos efetivos de solução e prevenção de litígios, e que a sua apropriada disciplina tem reduzido a excessiva judicialização dos conflitos de interesses e a quantidade de recursos, já que busca resolver conflitos considerando uma perspectiva futura, visando restaurar as relações entre as partes para que retomem o convívio.

Nesse sentido, ao analisar o crescimento dos meios alternativos de solução de conflitos nos Estados Unidos, em especial, a mediação, afirma Oscar G. Chase, que "Mediation's constructive power is based on its informality and consensuality, both of which "allow parties to define problemas and goals in their own terms, thus validating the importance of problems and goals in the parties'lives" ${ }^{21}$ (CHASE, 2005, p. 110).

A autocomposição ocorre por meio de técnicas que estimulam a aproximação das partes e a resolução de controvérsias, de uma forma menos traumática, uma vez que não é imposta por uma decisão adjudicada, revelando-se mais eficiente na solução de conflitos, diante da manifestação espontânea de vontade das partes e aceitação mútua quanto às questões existentes, obtida por meio do consenso, em prol da pacificação social. Destaca-se, assim, a importância da atuação extrajudicial, por meio das serventias extrajudiciais, uma vez que um agente mais próximo da comunidade $^{22}$ está mais apto a analisar o caso de forma equitativa, no intuito de solucionar os conflitos que impedem o retorno a convivência social.

Os meios alternativos de solução de conflitos advindos do movimento de desjudicialização, como a mediação e a conciliação, devem ser estimulados e difundidos, portanto, sob a égide do pós-positivismo, como formas democráticas de exercício da cidadania, uma vez que todos os envolvidos no problema possuem liberdade para discutir sobre suas razões em posições igualitárias, chegando a um consenso que será o mais adequado a eles e que resultará numa melhor aceitação do resultado, promovendo uma via de acesso capaz de assegurar a efetividade do princípio fundamental da dignidade da pessoa humana mediante a ampliação do acesso à justiça e

20 Sob uma perspectiva comunitarista, pode-se dizer que ao estabelecer uma política pública de estímulo à resolução consensual de conflitos, o Conselho Nacional de Justiça apresentou um modelo em que se busca ampliar o acesso à justiça e desenvolver hábitos corretos, que façam indivíduos de bom caráter, já que é daí que decorre a educação moral (SANDEL, 2012, p. 245).

21 Em livre tradução: "O poder construtivo da mediação é baseado em sua informalidade e consensualidade, os quais 'permitem que as partes definam os problemas e as metas em seus próprios termos, validando, assim, a importância desses problemas e metas em suas vidas". (Tradução nossa).

22 Segundo análise de Oscar Chase, um dos efeitos mais revolucionários desses meios de resolução de conflitos, é o que ele chama de criação de justiça da vizinhança: "Creation of neighborhood justice centers for the mediation of Community disputes" (2005, p. 96). 
à valorização da autonomia privada ${ }^{23}$.

\section{CONSIDERAÇÕES FINAIS}

A crescente judicialização das relações sociais foi determinante para a crise verificada no Judiciário a partir de meados do século XX. Esse cenário vem ao encontro da busca pela constitucionalização e efetivação de direitos fundamentais, diante da complexidade da sociedade atual e da insegurança em relação à efetividade da atividade jurisdicional.

$\mathrm{O}$ acesso à Justiça não pode mais ser contextualizado nos acanhados limites dos órgãos judiciais existentes, limitado na visão formal de mero acesso aos tribunais. Considerando a constituição Federal como um sistema aberto de princípios e regras, deve aquele direito ser visualizado como meio de realização dos direitos fundamentais e de consolidação de um Estado democrático de direito, devendo a ele ser dada a interpretação mais ampla possível, sob a égide pós-positivista.

Os entraves que envolvem a prestação jurisdicional não podem mais constituir óbice para a realização efetiva da justiça, devendo ser promovido pelo Estado o acesso a uma ordem jurídica justa e efetiva, mediante uma política pública que estimule a opção pelos meios alternativos de resolução de conflitos, assegurando o respeito à autonomia das partes sem olvidar a segurança jurídica.

Essas políticas encontram na via extrajudicial sua saída mais viável, o que vem sendo realizado por meio da desjudicialização, um processo que vem ganhando espaço já há alguns anos, e que permite a realização de mediação e conciliação como forma de resolver conflitos nas serventias extrajudiciais, consagrando a justiça coexistencial.

Com a autocomposição os interessados podem livremente definir a solução mais adequada para seus problemas jurídicos, num ambiente democrático, em que o diálogo é estimulado, promovendo a cidadania e a solidariedade social, como pressupostos para a consolidação da dignidade da pessoa humana.

\section{REFERÊNCIAS}

BARCELLOS, Ana Paula de. A eficácia jurídica dos princípios constitucionais: o princípio da dignidade da pessoa humana. Rio de Janeiro: Renovar, 2002.

BARROSO, Luis Roberto. Neoconstitucionalismo e constitucionalização do Direito: (O triunfo tardio do direito constitucional no Brasil). Revista de Direito Administrativo, Rio de Janeiro, v. 240, p. 1-42, abr., 2005. Disponível em: http://bibliotecadigital.fgv.br/ojs/index.php/rda/article/ view/43618/44695. Acesso em: 18 nov. 2018.

\section{BARROSO, Luis Roberto. Fundamentos Teóricos e Filosóficos do Novo Direito Constitucional}

23 Corrobora esse entendimento a PEC $\mathrm{n}^{\circ}$ 108/2015 que tramita no Congresso Nacional e busca acrescentar o inciso LXXIX ao art. $5^{\circ}$, da Constituição Federal, de forma a estabelecer o emprego de meios extrajudiciais de solução de conflitos como um direito fundamental (BRASIL, 2015). 
Brasileiro (pós-modernidade, teoria crítica e pós-positivismo). In: BARROSO, Luis Roberto (org.). A nova interpretação constitucional: ponderação, direitos fundamentais e relações privadas. 2. ed. Rio de Janeiro: Renovar, 2006. p.1-48.

BITTAR, Eduardo C. B.; ALMEIDA, Guilherme Assis de. Curso de filosofia do direito. 13. ed. São Paulo: Atlas, 2018.

BOBBIO, Norberto. O positivismo jurídico: lições de filosofia do direito. São Paulo: Ícone, 1995.

BONAVIDES, Paulo. Curso de direito constitucional. 13. ed. São Paulo: Malheiros, 2003.

BRASIL. Senado Federal. Proposta de Emenda à Constituição n ${ }^{\circ}$ 108, de 2015. Acrescenta inciso LXXIX ao art. $5^{\circ}$ da Constituição Federal, para estabelecer o emprego de meios extrajudiciais de solução de conflitos como um direito fundamental. Brasília: Senado Federal, 2015. Disponível em: https://www25.senado.leg.br/web/atividade/materias/-/materia/122592. Acesso em: 18 jun. 2018.

CALSAMIGLIA, Albert. Postpositivismo. Doxa, Alicante, v. 21, n. 1, 1998. Disponível em: file://C:/Users/rinaldorodrigues/Desktop/postpositivismo-0.pdf. Acesso em: 18 nov. 2018.

CAPPELLETTI, Mauro. Problemas de reforma do processo civil nas sociedades contemporâneas. Revista de Processo, São Paulo, ano 17, n. 65, 1992.

CAPPELlETTI, Mauro; GARTH, Bryant. Acesso à justiça. Porto Alegre: Sergio Antônio Fabris, 1988.

CHASE, Oscar G. Law, culture, and ritual: disputing systems in cross-cultural context. New York University Press: New York, 2005.

DINAMARCO, Cândido Rangel. Instrumentalidade do processo. São Paulo: Malheiros Editores, 1996.

DWORKIN, Ronald. Levando os direitos a sério. São Paulo: Martins Fontes, 2002.

FERNANDES, Ricardo Vieira de Carvalho; BICALHO, Guilherme Pereira Dolabella. Do Positivismo ao pós-positivismo jurídico: o atual paradigma jusfilosófico constitucional. Revista de Informação Legislativa, Brasília, v. 48, n. 189, p. 105-131, jan./mar., 2011.

FIGUEROA, Alfonso García. La Teoria del Derecho em Tiempos de Constitucionalismo. In: CARBONEL, Miguel (org.). Neoconstitucionalismo(s). Madrid: Trotta, 2003. p.159-186.

GOMES, Sergio Alves. Hermenêutica constitucional: um contributo à construção do estado democrático de direito. Curitiba: Juruá, 2011.

MENDES, Aluisio Gonçalves de Castro; SILVA, Larissa Clare Pochmann. Acesso à justiça: uma releitura da obra de Mauro Capelletti e Bryant Garth a partir do Brasil 40 anos depois. Quaestio Juris, Rio de Janeiro, v. 8, n. 3, p. 1827-1858, 2015. Disponível em: http://www.e-publicacoes. uerj.br/index.php/quaestioiuris/article/view/19385. Acesso em: 22 jul. 2018.

MOREIRA, Eduardo Ribeiro. Neoconstitucionalismo: a invasão da constituição. São Paulo: 
Método, 2008.

MUNIZ, Tânia Lobo. O conflito, os modelos de solução, o acesso à justiça e a estrutura oficial de solução de conflitos. In: MUNIZ, Tânia Lobo; ARAÚJO JR., Miguel Etinger. (org.). Estudos em direito negocial e os meios contemporâneos de solução de conflitos. Birigui: Boreal Editora, 2014. v. 1, p. 28-68.

PEDROSO, João et al. O acesso ao direito e à justiça: um direito fundamental em questão. Coimbra: Observatório Permanente da Justiça Portuguesa: Centro de Estudos Sociais, 2002.

REALE, Miguel. Lições preliminares de direito. 25. ed. São Paulo: Saraiva, 2001.

SANDEL, Michael J. Justiça: o que é fazer a coisa certa. Tradução de Heloisa Matias e Maria Alice Máximo. 6. ed. Rio de Janeiro: Civilização Brasileira, 2012.

SARDINHA, Cristiano de Lima Vaz. Cartórios e acesso à justiça: a contribuição das serventias extrajudiciais para a sociedade contemporânea, como alternativa ao poder judiciário. Salvador: Editora Jus Podivm, 2018.

SARLET, Ingo Wolfgang. Dignidade da pessoa humana e direitos fundamentais. Porto Alegre: Livraria do Advogado, 2001.

SARMENTO, Daniel. O neoconstitucionalismo no brasil: riscos e possibilidades. In:

SARMENTO, Daniel. Filosofia e teoria constitucional contemporânea. Rio de Janeiro: Lumen Juris, 2009. p. 113-146.

SUTER, José Ricardo. Mediação no direito de família: gestão democrática de conflitos. Rio de Janeiro: Lumen Juris, 2018.

SUTER, José Ricardo; CACHAPUZ, Rozane da Rosa. Mediação e conciliação como meios de resolução de conflitos e acesso à justiça. In: ENCONTRO INTERNACIONAL DO CONPEDI. 5., 2016, Florianópolis. Anais [...]. Florianópolis: CONPEDI, 2016. p. 58-75.

TARTUCE, Fernanda. Mediação nos conflitos civis. 4. ed. São Paulo: Método, 2018.

WATANABE, Kazuo. Política Pública do Poder Judiciário Nacional para tratamento adequado dos conflitos de interesses. Revista de Processo, São Paulo, ano 36, v. 195, p. 381-389, maio, 2011.

Como citar: MINELLI, Daiane Schwabe; GOMES, Sergio Alves. A desjudicialização e os meios alternativos de resolução de conflitos sob a égide do pós-positivismo. Revista do Direito Público, Londrina, v. 14, n. 2, p. 151-167, ago. 2019. DOI: 10.5433/24157-108104-1.2019v14n2p. 151. ISSN: 1980-511X

Recebido em: 13/05/2019.

Aprovado em: 14/06/2019. 